Steinfield, H., Mooney, H.A., Schneider, F. and Neville, L. E. Livestock in a changing landscape: Drivers, consequences, and responses (Volume 1) and Gerber, P., Mooney, H. A., Dijkman, J., Tarawali, S. and de Haan, C. Livestock in a changing landscape: Experiences and Regional perspectives (Volume 2)

\section{Gufu Oba}

Correspondence: gufu.oba@umb. no Department of International Environment and Development Studies, Norwegian University of Life Sciences, PO Box 5003, N-1432 Ås, Norway

\section{Book details}

Steinfield $\mathrm{H}$, Mooney HA, Schneider $\mathrm{F}$ and Neville LE: Livestock in a changing landscape: Drivers, consequences, and responses Island Press, Washington DC; 2010. xiv+585 pages. ISBN 978-1-59726-671-0

Gerber P, Mooney HA, Dijkman J, Tarawali S and de Haan C: Livestock in a changing landscape: Experiences and Regional perspectives Island Press, Washington DC; 2010. ISBN 978-1-59726-673-4

There is little doubt that some of the contributors to the two volumes are already well known by their readers. The authors have made an important attempt to review a vast literature on global livestock production systems. In my view this attempt by the authors to provide global perspectives of shifting livestock production has benefitted many agencies (as is shown by the list of supporting institutions). The global and regional attention given to livestock sector production is therefore a welcome development. In volume 1 (which consists of 20 Chapters), the focus is on developed and developing countries. Global livestock production is consumer driven, as the demand for food (particularly on the part of the growing urban populations) increases. By highlighting the different geographical dimensions of the production and the transfer of livestock-based production, the book aims to show linkages between the formal and informal market food chains. The emphasis is on environmental impacts. Livestock production and its impacts on the immediate environment is influenced by multiple drivers. The book identifies these drivers as population growth, shifts in technology and rising demand for human food and animal feed. All of these are responsible for a move from agriculture to livestock production. However, these developments have not

C 2011 Oba; licensee Springer. This is an Open Access article distributed under the terms of the Creative Commons Attribution License (http://creativecommons.org/licenses/by/2.0), which permits unrestricted use, distribution, and reproduction in any medium, provided the original work is properly cited. 
been felt equally across the developed and developing countries and between low and high population density countries. Greater demands for higher calorific intake in such regions as South-East Asia and East Asia, which also have a higher consumption index, show them to be the main shifters when it comes to livestock production. In subSaharan Africa, with a negative consumptive calorific index, demand is lower. The book in Volume 1 outlines the different systems of livestock production. The gradients of livestock production vary according to whether the system is extensive, mixed or intensive. Extensive systems, such as those practiced in the dry tropics, have low stocking rates and low quality feed from natural pastures. Extensive systems however require large grazing areas. The book shows that where the extensive systems break down because of land-use competition, the livestock production system shifts to smaller-scale mixed systems, such as those found in agro-pastoral systems. These systems are practiced in the developing countries, while in the developed countries, with their greater demand for food, livestock production tends to be intensive. In the intensive system, the economy of scale is more preferred to meet the increasing demands for livestock products than small scale units of production. These specialized systems rely on concentrate feed, and call for greater investment in technology and energy use.

A general thesis permeates the discussions in the two volumes. This is that livestock production systems have had effects on the environment. The authors of the Livestock in the Changing Landscape seem to have overemphasized the negative aspects of these impacts. With regard to the impact of livestock on biodiversity, the authors discuss both direct and indirect influences of livestock grazing and its impact on land cover. The authors suggest that the impact on the environment is mediated through human activities rather than through the direct impact of livestock. In extensive systems, where demand for feed exceeds the available natural pastures, the replacement of tropical forests by soya beans (for livestock feed) is believed to reduce biodiversity. However, the negative impact cannot be attributed to increased livestock production alone. Agriculture could be responsible for a greater loss of vegetation cover than that caused by livestock. As far as tropical pasture is concerned, the book's arguments with regard to overgrazing and soil loss are not substantiated. For example, evidence of a direct relationship between livestock and desertification on a global scale is tenuous. Such arguments fail to separate the effects of environmental drivers from anthropogenic and climatic drivers. In the wider global literature, there is some attempt (however limited) to compare different systems. The problem lies with the sources used, particularly where there are attempts to generalize which cannot be related to specific cases. For example, if one looks at the direct effects of increased carbon emissions and other greenhouse gases (which are highlighted in most of the chapters), livestock accounts for $9 \%$ of Global $\mathrm{CO}_{2}$, then the challenge is to calculate the balance between carbon emissions and carbon sequestration in livestock production systems.

In the intensive system where the production is specialized and the limited land is available (and this is often occupied by humans), environmental impacts are caused by problems related to the (mis)management of livestock waste. The high nutritional concentrations in the excreta and urine of animals are either directly discharged into water systems or their storage time is limited. Throughout the world, livestock produces 13 billion tonnes of waste per year (Plachter and Hampick 2010). The high N and $\mathrm{P}$ loads result in environmental pressures that are very costly to mitigate to 
environmentally acceptable levels (Volume 2). Yet even in such systems, one cannot simply transfer standards from one part of the globe to another; this is a consequence of local systems which are often unique, coupled with land scarcity. A pressing issue related to animal waste management and presence of large populations of livestock in close proximity to high density human habitats is the problem of zoonotics: there are frequent outbreaks of these diseases in crowded human urban environments. The effect of the foul air with its heavy loads of pathogens is emphasized in most of the chapters. In the well-known case of avian influenza, the transportation of live animals was disrupted throughout the world. The seriousness of this worldwide health hazard is warranted.

Structural changes at regional levels are reviewed in Volume 2 (10 chapters). The authors of Livestock in a changing landscape Experiences and Regional perspectives attempt to apply the drivers reviewed in Volume 1 to individual regions. The first chapter attempts to identify the global drivers that also influence regional livestock production. Livestock production performances are viewed from the point of view of their environmental impacts, the risks associated with diseases, and the economic and social contribution. The claim is that with intensification, the agro-industries are changing livestock production methods particularly when it comes to waste management.

In the chapter on the Eastern and the Horn of Africa (Chapter 2), there is an attempt to arrive at generalizations of the issues, but using rather unconvincing arguments. For example, the drivers identified (p. 7) are not systematically discussed. The decline in total livestock and the decline in livestock per capita are not distinguished. Yet, in the same line of argument, the authors directly correlate what they consider to be an increasing human population with the demand for livestock products, suggesting that the milk production and consumption is higher in East Africa and the Horn of Africa than in the rest of the sub-Saharan Africa. This analysis is overly simplistic. The chapter makes sweeping arguments regarding the role played by climatic change in 'increasing aridity and the expansion of deserts' (p. 9); it then attempts to link this to the melting glaciers of the East African Mountains. One would need a historical perspective to understand how the melting of glaciers over time is associated (albeit indirectly) with climatic change. The cause of aridity and deserts cannot be linked to recent changes without placing it in biogeographical and geomorphological contexts (Millington and Pye 1994). If the intention is to suggest that climatic change has influenced livestock production, then the links in the argument are tenuous.

Chapter 3 defines the drivers clearly, highlights the declining traditional systems, and shows that recent interventions have not been successful. The chapter draws attention to urbanization as a link between the production and the consumption chains. Livestock production can be seen as natural activity and is less dependent on industrial investment. The economy of the West African region is still based on subsistence farming, with livestock providing both the economic and social capital as well as the source of draught power for agricultural farming. Stall-feeding is becoming more common in peri-urban areas, while in the rural areas the link between livestock and crop cultivation remains strong. The herders combine transhumance grazing with use of crop residue as livestock feed; this is made available through mutually beneficial social arrangements. The reliance on donor support and the weakening of local institutions has, however, undermined any expansion in livestock production. The encroachments 
by crop cultivators on grazing lands squeezed livestock into limited areas for grazing, with a resulting reduction in the biodiversity of the grazing lands. While repeating views that ascribe land degradation and desertification to over-grazing by livestock, the authors of the chapter admit that 'there seem[s] to be insufficient data on actual soil conditions and/or productivity to support findings of inexorable and inevitable degradation and serious nutrient depletion' (p. 38). The authors place the responsibility for the loss of pastoral land on the exclusion of pastoralists from decision-making. Thus, the decline in resources was not followed by improved state intervention; rather, concessions were made in a 'piecemeal' fashion (p. 39). Consequently, increased urbanization and growing consumer demand have led to the intensification of production. The authors conclude that 'despite the positive response from farmers and communities to meet the growing demand in animal products in the context of shrinking resource base, there has been a widening gap between demand and domestic supply of animal products' (p. 49), thus making the West African region a net importer of livestock products.

Chapter 4 examines shifts in thinking regarding the role of livestock production in the Indian subcontinent. The environmental role of livestock is central to the arguments. The authors argue that the emphasis on the negative environmental impact of livestock needs to be re-examined in the light of changing livestock production systems. The main drivers of these changes are population increase and urbanization. However, the chapter argues that the consumption of livestock products, such as milk and eggs, is far larger in the rural areas than in the urban areas. General increases in production over the years, particularly with regard to poultry, are highlighted. The Indian data shows greater concentration of livestock production in the rural areas reflecting the close links between crop cultivation and the need for draught power. In India, in contrast with Africa, livestock feed is supplemented by concentrate feeds. This has socio-economic consequences: the authors argue that livestock production has not reduced the risk of poverty in rural areas. A second consequence relates to the communal pastures where most livestock production takes place. The shrinking communal resource base has forced a shift in animal farming in favour of small ruminants. The limited grazing areas are placed under greater pressure as extensive systems breaks down and are replaced by mixed systems, where farmers are forced to maintain small herds. The greatest disadvantage of this is that in a mixed system, integration between livestock and crop systems is not well established. The result of this is loss of nutrient recycling in the system. The main shift has been towards intensive poultry production in the urban areas. The main environmental consequences are greater green house emissions from the intensive urban based livestock production. The chapter outlines some of the policies that governments are adopting, such as improved natural resource management. The case studies show the inter-linkages between changing productions and the environment and the implications for policy improvements.

The Chapter on Brazil and Costa Rica (Chapter 5) provides an interesting comparative analysis of linkages between agricultural expansion and the policies adopted in the two countries. The chapter identifies the key drivers as market forces; it points to shifting relations between policies and the expansion or contraction of agricultural lands, deforestation and conservation. The chapter shows how policy can be an effective tool. For example, while Costa Rica, which is more conservation-oriented, reduced 
deforestation, the expansion of agriculture in Brazil involved clearing natural forests. In developing their arguments, the authors show the close links between market forces, agricultural expansion and deforestation. For example, in both countries credits to farmers resulted in the clearing of large areas of forest, while reduced credit facilities and the decline in the beef markets reduced the clearing of forest lands. Demand for beef by European countries and demand for animal feeds are the main drivers behind efforts to clear forests for the cultivation of soya beans. A consequence of the largescale destruction of tropical forests and their replacement by grasslands is a higher risk of land degradation. According to the authors, loss of biodiversity has resulted in a decline in the productivity of livestock per unit of land per year. However, the authors admit that the reported impacts are based on short-term studies: they state that 'there has been no long-term study to quantify the impacts of the resulting forest fragmentation' (p. 85). This cautious view is justified as most of the evidence is based on generalizations.

The intensification of livestock production in response to growing consumer demand in China and other East Asian and South-East Asian countries (Chapter 6) has transformed production from an extensive to an intensive system. China's growing human population requires increased livestock products. A greater demand for food is matched by an increase in incomes. There is a close link between large-scale industrial processing of livestock feed and the increased production of livestock. Intensification has a positive impact on the supply of food but is claimed to pose the greatest threat to the environment. These environmental impacts result from increased nutrient loads. Water pollution is one of the environmental threats, while in the drier Mongolian steppe the large livestock population is thought to increase the risk of desertification. The authors of the chapter do not explain that processes of desertification in Inner Mongolia are historical and have little to do with the present-day impact of livestock production. The chapter reviews the policies that are required if these environmental challenges are to be met. One such policy is the regulation of discharges of nutrient loads into waterways. There is an urgent need to develop standards for acceptable levels of pollution. While the impact of livestock is both positive and negative, it is the negatives that have been (over)emphasized.

Chapter 7 on The United States, like others in Volume 2, uses meta-analyses of data sources to reach conclusions on the roles played by the key drivers in livestock production systems. The USA is a leader in many aspects of livestock production, making use of both the extensive and intensive systems. There are geographical variations in the concentrations of intensive systems. Economies of scale are widely practiced. The trend is towards fewer and larger livestock farms, for example dairy farms. Large-scale production enables farmers to meet the economic demands -the small-scale producers would not be able to do this. This means that there is a shift towards growing animal feeds, such as high quality forage (for example, alfalfa). The success of the USA livestock industry depends on the transportation chains that allow products to reach consumers in different areas. The shift towards the use of grain as a source of animal feed and the increased use of fertilizers corresponds with an increase in manure loads, and this presents environmental problems. Large-scale livestock production produces manure in excess of the cyclical capacity of nutrient loads, and threatening to pollute water sources. Remedies are to be found in pricing policies, the legislation of water quality 
controls, improved feeds and the recycling of manure. The authors conclude that the most important remedy is increased nutrient cycling in the surrounding landscapes.

Chapter 8, on Denmark and the European Union, focuses on the impact of livestock production on nutrient management. Regulatory systems with a regional approach, including utilization of animal wastes and increased storage time, are advocated. The policy regarding nutrient loads is aimed at increasing the efficiency of nutrient uptake and reducing the costs of regulating nutrients. The livestock-agriculture mixed system that has historically been part of the Danish agriculture allowed nutrient cycling between farms and livestock production. However, this is being threatened in the intensive system by greater concentrations of nutrients leaching into waterways, including ground water. The policy aims at avoidance of nutrient pollution by improving slurry through increased intervals of application on the farms. The focus is on the management of aquatic systems by reducing the leaching of nutrients. The actions taken are based on the cost effectiveness of reducing nutrient loads.

Chapter 9, on the Nestlé food chains, considers the links between animal food production through local, regional and international food chains that have a turnover of billions of dollars. The growth of the dairy industry and the collection of milk from small-scale producers demand an improvement in environmental performance through the reduced use of water and energy. Food safety and improved disease controls and a greater demand for livestock products have environmental implications. However, the varied scales of production mean that a uniform standard is not achievable. Developed and developing countries allow different standards, although the goals of the food chain industry remain the improvement of milk quality and supply quantities to meet the growing demand. These goals also include improved monitoring of contaminations. Through case studies the authors show the challenges of working with small-scale farmers, while maintaining regular delivery and rigorous quality checks. In terms of reducing environmental impacts, food chains promote reforestation, soil conservation and the proper use of energy, all of which would reduce the release of greenhouse gases. In their conclusion the authors advocate that the industry should engage stakeholders with a view to reducing environmental impacts.

In the concluding chapter in Volume 2, the editors revisit structural changes in livestock production to meet the growing demand in highly populated regions such as East Asia. They show how shifts towards the intensification of livestock production have almost driven small-scale producers out of business. The main challenge is the growing adverse impact on the environment. Countries have responded through policies that regulate excess nutrient loads and reduce pollution of water sources. The editors observe that the beneficiaries of increased livestock production are the growing numbers of consumers in urban environments, while the losers are the small-scale farmers. In the long-term, therefore land shortages might undermine efforts to achieve the levels of production that are needed if the demand is to be met. This will be particularly critical in the developing countries.

Finally, there is little doubt that Livestock in a Changing landscape provides an enormous amount of information on the global and regional drivers of livestock production. Individual countries that are developing their livestock industry will learn lessons from others. One shortcoming of the book is the lack of cross-referencing between chapters; this would have reduced the frequent repetition of similar material. The 
second shortcoming is the emphasis on negative role livestock plays on the environment without counterbalancing with the positive roles. The third is lack of clarity on the targeted users of the book although the policy makers seem to be the main target. As a reference source for academic institutions, the book will be of limited value partly for its lack of rigor and sometimes reliance on vague deductions on the roles played by livestock on environment. Repetitions of same materials in different chapters will make readers uncomfortable given the huge material to be read.

\section{Authors' information}

Gufu Oba

The author is Professor at Noragric, Department of International Environment and Development Studies, Norwegian University of Life Sciences, PO Box 5003, N-1432 Ås, Norway. He has extensively published on topics related to rangeland management, Pastoralism and livestock production. He can be contacted at E-mail: gufu.oba@umb.no.

\section{Competing interests}

The authors declare that they have no competing interests.

Received: 30 March 2011 Accepted: 9 May 2011 Published: 9 May 2011

\section{References}

Millington, A.C. and Pye, K (eds) 1994. Environmental change in drylands: Biogeographical and geomorphological perspectives, John Wiley \& Sons, Chichester.

Plachter H. and Hampicke (eds) 2010. Large scale-livestock grazing: A management tool for nature conservation, SpringerVerlag Berlin.

doi:10.1186/2041-7136-1-10

Cite this article as: Oba: Steinfield, H., Mooney, H.A., Schneider, F. and Neville, L. E. Livestock in a changing landscape: Drivers, consequences, and responses (Volume 1) and Gerber, P., Mooney, H. A., Dijkman, J., Tarawali, S. and de Haan, C. Livestock in a changing landscape: Experiences and Regional perspectives (Volume 2). Pastoralism: Research, Policy and Practice 2011 1:10.

\section{Submit your manuscript to a SpringerOpen ${ }^{\circ}$} journal and benefit from:

- Convenient online submission

- Rigorous peer review

- Immediate publication on acceptance

- Open access: articles freely available online

- High visibility within the field

- Retaining the copyright to your article

Submit your next manuscript at $\mathbf{s p r i n g e r o p e n . c o m ~}$ 